International Journal of Current Advanced Research

ISSN: O: 2319-6475, ISSN: P: 2319 - 6505, Impact Factor: SJIF: 5.995

Available Online at www.journalijcar.org

Volume 6; Issue 4; April 2017; Page No. 3114-3116

DOI: http://dx.doi.org/10.24327/ijcar.2017.3116.0197

\title{
MORALE OF ANTIBIOTICS USAGE IN DENTISTRY
}

\author{
Manimegalai.A.G and Gayathri.S
}

Sathyabama University Dental College and Hospital, Chennai

\begin{tabular}{l}
\hline A R T I C L E I N F O \\
Article History: \\
Received $19^{\text {th }}$ January, 2017 \\
Received in revised form $8^{\text {th }}$ February, 2017 \\
Accepted $22^{\text {nd }}$ March, 2017 \\
Published online $28^{\text {th }}$ April, 2017 \\
\end{tabular}

Key words:

Antibiotics, Antibiotic resistance,

Superbug

\begin{abstract}
A B S T R A C T
Antibiotics are commonly prescribed by dentists for treatment and prevention of oral infections. Antibiotics are life saving drugs. However inappropriate prescribing and excessive use of antibiotics are major factors in development of antibiotics resistance. Dentists should play a pivotal role in judicious use of antimicrobials to prevent the antimicrobial resistance. This review is to highlight the importance of use of antibiotics in dentistry, scientific challenges in finding a new antibiotic, recommendations for minimizing resistance and thus how we can curb the growing global problem of developing antibiotic resistance.
\end{abstract}

Copyright $\bigcirc 2017$ Manimegalai.A.G and Gayathri.S. This is an open access article distributed under the Creative Commons Attribution License, which permits unrestricted use, distribution, and reproduction in any medium, provided the original work is properly cited.

\section{INTRODUCTION}

The oral diseases presented to the dentist are primarily inflammatory conditions that may be associated pain. ${ }^{1}$ Dental practitioners regularly prescribe antibiotics for the prophylactic or therapeutic purposes to manage oral infections. Antibiotics are not an alternative to dental intervention; they are adjunct and never the first line of treatment modality. Antibiotics overuse and misuse among dentists is substantial.

Ever since the early work of Sir Alexander Fleming in 1929 when Pencillin became the first "Miracle drug" innumerable lives have been saved from diseases such as pneumonia, wound sepsis, and bacteremias. Dentists were also benefitted from discovery of pencillin because most odontogenic infections were caused by pencillin sensitive organisms. These were the most frequently used and perhaps misused drugs. We truly live in the "Antibiotic Era". ${ }^{2}$

Drug resistance is not a new concept. In his 1945 Nobel lecture, Sir Alexander Fleming warned that: "there is the danger that the ignorant man may easily under dose himself and by exposing his microbes to non-lethal quantities of the drug make them resistant". His fears materialized just four years after mass treatment with the drug when pencillin resistant strains became prevalent. ${ }^{3}$ The overuse of antibiotics has lead to development of global health concern which is development of antibiotic resistance. Dentists prescribe between $7 \%$ to $11 \%$ of all common antibiotics (betalactams, macrolides, tetracyclines, clindamycin, metronidazole). ${ }^{4}$

*Corresponding author: Manimegalai.A.G

Sathyabama University Dental College and Hospital,

Chennai
We have now entered into an era where some bacterial species are resistant to full range of antibiotics, presently available, with the methicillin resistant staphylococcus aureus being the most widely known example of esterase resistance commonly known as 'Superbug', 1,5,6

This growing problem of antibiotic resistance has contributed significantly to the morbidity and mortality of infectious diseases, with death rates for communicable diseases rising again. Moreover antibiotics are societal drugs that affect microbial resistance not only in the person taking the drug but also everyone, because resistance genes are easily passed via personal contacts, fomites, human and animal refuse. According to World health organization this growing problem of antibiotic resistance was announced the theme for the year 2011 as "Antibiotic Resistance- No Action today - No cure tomorrow". 1, 7,8

\section{Mechanisms by which antibiotic resistance develop: ${ }^{1,9,10}$}

Bacteria resist the effects of antibiotics by using the following genetic strategies, with thousands of variations: Microorganism's primary function is to reproduce, thrive and spread efficiently. They adapt to their environments and change in ways that assist their survival. If an antibiotic stops their ability to grow, genetic changes occur within the microorganism. This happens by:

Selective pressure: In presence of the drug, microbes are either killed or, if they carry resistance genes, survive. These organisms and their progeny will become dominant.

Mutation: during replication mutations arise and some of these mutations help microbes to survive when exposed to 
antibiotics and modifying antimicrobial targets, by mutation, so that drugs cannot recognize them

Gene transfer: microbes get genes by transfer of DNA via plasmid Preventing antibiotics from entering by creating a "biofilm" or otherwise reducing permeability; and producing destructive enzymes to neutralize antibiotics;

\section{Other causes include}

Inappropriate use and improper diagnosis: failure to give correct antimicrobial therapy without proper clinical and laboratory diagnosis. Antibiotics for viral origin infections, patient related factors, use of monotherapy, commercial promotion, over counter sale of antibiotics, inadequate culture and sensitive test procedures.

Duration of therapy and dose of the drug plays an important role. Individuals can harbor resistant bacterial strains for up to three months following antibiotic use.

According to a systematic review, systemic antibiotics should be considered if there is a spreading infection that signals failure of local host responses in abating the advancing bacterial irritants, or if the patient's medical history includes the condition or the diseases known to reduce the host defense or expose the patient to high systemic risk. ${ }^{4,11}$

\section{Scientific challenges faced in discovery of new antibiotics}

For half a century, from 1940 to 1990, the repeated and successful response to emerging resistance was to discover new antibacterials. In recent years this strategy has failed, with resistance accumulating faster than new antibiotics have been developed.

Antibiotics, in particular, have a poor return on investment because they are taken for a short period of time and cure their target disease. In contrast, drugs that treat chronic illness, such as high blood pressure, are taken daily for the rest of a patient's life. "Companies have figured out that they make a lot more money selling the latter drugs than they do selling antibiotics," Spellberg says, highlighting the lack of incentive for companies to develop antibiotics.

That's why many companies have stopped developing antibiotics altogether. ${ }^{12,13}$ only five major pharmaceutical companies - albeit five of the biggest - GlaxoSmithKline, Novartis, AstraZeneca, Merck and Pfizer, still had active antibacterial discovery programmes in $2008 .^{14}$

Adding to the grim picture, a comprehensive study of antibiotic development, covering innovative, small firms, as well as pharma giants, found in 2008 that only 15 antibiotics of 167 under development had a new mechanism of action with the potential to meet the challenge of multidrug resistance. According to the 2008 study, every year at least 25000 patients in the European Union alone die from an infection caused by multidrug-resistant bacteria and estimated additional health-care costs and productivity losses are at least 1.5 billion Euros. Drug companies spend $\$ 100$ million for a phase III program in development of antibiotics. The total average cost of $\$ 2.9$ billion for developing a new drug. ${ }^{15}$ Thus discovery and development of antibiotics have become, scientifically more complex, more expensive and time consuming. Antibiotics development has come to stagnate at present. 16 antibiotics were approved by FDA for use in human in the year 1983-1987 compared to 2 antibiotics which was approved in the year 2008 till date. We have had no new classes of antibiotics to treat gram negative bacilli for more than 40 years, But the antibiotic resistance is spreading like wild fire. ${ }^{16}$

\section{DISCUSSION}

Data reported from various countries indicate that antibiotics use is wide spread and so is the development of resistance. Amoxycillin is the most commonly prescribed drug. Antibiotic-resistant infections contribute to the financial burden on healthcare systems. In Europe, they cost an estimated $€ 1.5$ billion annually, including healthcare expenditures and productivity losses. In the United States, the annual cost to the healthcare system is as much as $\$ 20$ billion, and productivity losses total another $\$ 35$ billion. This is one example of the trends of resistance and its effects globally. India is one of the top global consumers of antibiotics overall in 2010, which was 13 billion SU; followed by China, 10 billion SU; and the United States, 7 billion SU. However, in per capita terms among these countries, the United States led in 2010 with $22 \mathrm{SU}$ per person, compared with $11 \mathrm{SU}$ in India and $7 \mathrm{SU}$ in China ${ }^{17}$

Various studies conducted in India showed, poor KAPKnowledge, attitude, practice regarding antimicrobial use in dentistry thereby conferring increasing antimicrobial resistance. ${ }^{18}$

Majority of dentists prescribe antibiotics for managing oral diseases expect for orthodontic treatment. BDS (Bachelor of Dental Surgery) graduates relied more on antibiotics to manage oral diseases than MDS (Master of Dental Surgery), which may be due to inadequate understanding of the disease, less skill and competency in carrying out the operative intervention measures. 4,19

With regard to duration of prescription $74 \%$ General dental practioners prescribe 3 day course, $60 \%$ of pediatric dentists resorted to 5 day course. Evidence also indicates that inadequate prescribing patterns may be due to inadequate knowledge about the diseases ${ }^{.0}$ Cross sectional survey shows that majority of dental practioners over prescribe antibiotics and were unaware of the recent antibiotic guidelines laid by government of India. ${ }^{21}$

\section{Recommendations to prevent antibiotic resistance}

Antibiotic resistance is one of the biggest challenges we face in modern healthcare. We as a part of health care professionals should contribute to prevent development of antibiotic resistance. Systemic antimicrobials should be used only as an adjunct and not as the first line of treatment. Antibiotics should be considered when there local spread of infection, elevated temperature, lynphadenopathy, cellulitis and in immune compromised patients. Six strategies may help to slow the development of resistance: ${ }^{17}$

1. Reducing the need of antibiotics by improved water, sanitization and immunization

2. Improve hospital infection control and antibiotic stewardship

3. Change incentives that encourage antibiotic overuse and misuse to incentives that encourage antibiotic stewardship

4. Reduce the use of antibiotics in livestock and agriculture 
5. Educate and inform the health professionals and public about judicious use of antibiotics

6. Ensure political commitment to meet the treat of resistance

The installation of a surveillance system, accompanied by audit to ascertain the numbers of prescriptions and their appropriateness, to highlight areas of knowledge that are lacking in dental practice is needed. Updating information on latest diagnostic tests, culture and sensitivity tests, following recommended guidelines and dosage, Aseptic working environment can help to curb this global health problem.

\section{CONCLUSION}

Judicious use of antibiotics is essential to encounter the threat of developing resistance. The need of the hour is to weigh the pros and cons of antibiotics before prescribing to patients. Action must to taken now to lessen the impact of resistance in future.

\section{References}

1. Suchi K and Praveen J. Antibiotics in dentistry- A boom or Bane? J Dent App.2015;2(1):132-137

2. Jain $\mathrm{MK}$ and Oswal $\mathrm{S}$ Antibiotics in dentistry -An art and science Annals of dental speciality 2013; 2(1):2026

3. Alexander Fleming Pencillin. Nobel Lecture, December 11, 1945. Available from: http://www.nobelprize.org/nobelprizes/medicine/laurea tes/1945/fleming-lecture.pdf

4. Dr Karibasappa G N, Dr Sujatha A IOSR-JDMS feb 2013; 2(13):112-118

5. Lewis MAO. Why we must reduce dental prescription of antibiotics: European Union Antibiotic Awareness Day. Br Dent $J$ 2008;205:537-538

6. Cleveland JI, Kohn WC. Antimicrobial resistance and dental care: a CDC prespective. Dent Abstr 1998;108110

7. Khan K, Muenning P, Behta M, Zivin JG. Global drug resistance patterns and the management of latent tuberculosis infectionin immigrants to the United States. N Engl J Med 2002;347:1850-1859

8. Musoko RN, Revathi G. emergence of multidrugresistant gram negative organisms in a neonatal unit and the therapeutic implications. $J$ Trop Pediatr $2000 ; 46: 86-91$
9. Daily YM, Martin MV. Are antibiotics being used appropriately for emergency dental treatment? Br Dent $J$ 2001;191:391-393

10. McKenzie D, Rawlins M, Mar CD. Antimicrobial stewardship: What's it all about? Aust Prescr 2013;36:116-120

11. Fauad AF. Are antibiotics effective for endodontic pain? An evidence based review. Endodontics topics 2002;3:52-66

12. David M. Livermore Discovery research: the scientific challenge of finding new antibiotics $J$ Antimicrob Chemother 2011;66 (9): 1941-1944

13. Projan SJ. Why is Big Pharma getting out of antibacterial drug discovery? Curr Opin Microbiol, 2003;6:427-430

14. Bull World Health Organ 2011;89:88-89|

15. doi:10.2471/BLT.11.030211.Available from: http://www.who.int/bulletin/volumes/89/2/11030211.pdf

16. Jason Millman. November 18, 2014. Does it really cost $\$ 2.6$ billion to develop a new drug. Avaliable from: https://www.washingtonpost.com/news/wonk/wp/2014 /11/18/does-it-really-cost-2-6-billion-to-develop-anew-drug/?utm_term $=$.f6b7bfb3d601

17. B Spellberg New antibiotic development: Barriers and opportunities in 2012 Newsletter vol30 (1) http://emerald.tufts.edu/med/apua/news/newsnewsletter-vol-30-no-1-2.shtml

18. Center for Disease Dynamics, Economics and Policy.2015 State of World's Antibiotics 2015. CDDEP: Washington, D.C

19. Singh DP, Sampath N, Mahuli AV, Yadav H, Mahuli SA, Yadav R. Knowledge regarding antibiotic drug action and prescription practices among dentist in Jaipur city, Rajasthan. J Dent Res Rev 2015; 2:127-9.

20. Antibiotic over usage and resistance: A cross-sectional survey among pediatric dentists

21. Konde S, Jairam LS, Peethambar P, Noojady SR, Kumar NC. Antibiotic overusage and resistance: A cross sectional survey among pediatric dentists. $J$ Indian Soc Pedod Prev Dent 2016;34:145-51

22. Sivaramakrishnan Gowri, Deeksha Mehta, Sridharan Kannan Antibiotics use in dentistry: A cross sectional study from a developing country. J oral facial sciences July 2015; 7(2):90-94

\section{How to cite this article:}

Manimegalai.A.G and Gayathri.S (2017) ' Morale of Antibiotics Usage In Dentistry', International Journal of Current Advanced Research, 06(04), pp. 3114-3116.

DOI: http://dx.doi.org/10.24327/ijcar.2017.3116.0197 